\title{
Low shrinkage composite resins and occlusal matrix technique: association for direct extensive resin restoration
}

Leonardo Fernandes da Cunha ${ }^{a}$, Samantha Schaffer Pugsley Baratto ${ }^{b}$, Carla Castiglia Gonzaga ${ }^{a}$, Gisele Maria Correr ${ }^{a}$

\begin{abstract}
INTRODUCTION: Ensuring adequate occlusal contacts and anatomy shape and form is always a challenge when placing extensive direct posterior composite resin restorations. The use of a correct technique, such as, an occlusal matrix can reproduce occlusal morphology more precisely. Additionally, recently, silorane-based or bulk fill composite resin present low shrinkage and were specifically designed for restoring posterior teeth.

CASE REPORT: This report presents the clinical application of a low shrinkage composite resin system with a preoperative occlusal matrix in extensive composite resin restoration of a molar with hypomineralization. Acrylic resin was applied over the waxed tooth to copy the anatomic details Cavity was prepared and bonding system was applied. Definitive layer in the occlusal matrix was applied and stabilized in position. Once curing was complete, occlusal matrix and resin excess were removed using a surgical blade.

CONCLUSION: The application of these materials with occlusal matrix can provide a simpler technical approach, saving time and improving esthetic results.
\end{abstract}

Keywords: extensive direct restoration; silorane-based composite resin; bulk fill composite; occlusal matrix.

\section{Resinas compostas de baixa contração e técnica de matriz oclusal: associação para restauração extensa posterior}

\section{RESUMO}

INTRODUÇÃO: Assegurar contatos oclusais adequados e anatomia correta são sempre um desafio ao realizar restaurações de resina composta direta extensa em dentes posteriores. O uso de uma técnica correta, como, uma matriz oclusal pode reproduzir a morfologia oclusal mais precisa. Além disso, recentemente, a resina composta com base em silorano ou bulk fill apresentam baixa contração e foram projetadas especificamente para restaurar os dentes posteriores.

RELATO DO CASO: O presente relato apresenta a aplicação clínica de um sistema de resina composta de baixa contração com uma matriz oclusal pré-operatória na restauração extensa de resina composta de um molar com hipominalização. Uma matriz de resina acrílica foi aplicada sobre o dente encerado para copiar os detalhes anatômicos. A cavidade foi preparada e o sistema adesivo foi aplicado. A camada final de resina foi aplicada na matriz oclusal e estabilizada na posição. Uma vez que a cura foi finalizada, a matriz oclusal foi removida e o excesso de resina foi removido.

CONCLUSÃO: A aplicação destes materiais com matriz oclusal pode proporcionar uma abordagem técnica mais simples, economizando tempo e melhorando os resultados estéticos.

Palavras-chave: restauração dentária permanente; resinas de silorano; resinas compostas; ajuste oclusal.

\author{
Professor, Graduate Program of Dentistry, \\ Universidade Positivo \\ ${ }^{\mathrm{b}}$ Graduate student, Graduate Program of Dentistry, \\ Universidade Positivo
}

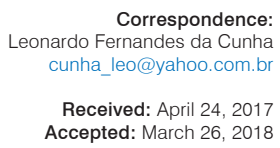

Accepted: March 26, 2018

Conflict of Interests: The authors state that there are no financial and personal conflicts of interest that could have inappropriately influenced their work.

Copyright: (c) 2017 da Cunha et al:; licensee EDIPUCRS.

This work is licensed under a Creative Commons Attribution 4.0 International License. 


\section{INTRODUCTION}

Since the introduction of low-shrinkage restorative materials, restoration of posterior teeth has become a routine procedure in many dental practices [1]. Many restoration techniques to reestablish function and improve esthetics can now be performed in dental clinics [2]. Nevertheless, the most advantageous protocol for ensuring the clinical success of direct extensive composite resin restoration is unclear.

The reestablishment of the occlusal morphology for posterior restorations is both time consuming and dependent on professional ability [3]. Restorative planning is recommended to attain restorative success; thus, wax-up can be used. In some situations, chairside fabrication of an occlusal matrix is recommended before cavity preparation ensues. The occlusal matrix may be used to contour the final resin composite restoration [4]. This technique can also be used in direct extensive composite resin restoration. Therefore, an optimal method for restoring posterior composite restorations has become an alternative.

The stress development resulting from the polymerization process is considered a major challenge in dental restoration. In order to reduce the stress in photoactivated composites, clinical application techniques have been developed and studied, but the results are controversial. Consequently, modifications of the resin matrix formulations have been developed to address the problem $[1,5,6]$. The use of silorane-based and bulk fill composite materials have become widespread in dental offices to provide solutions for dental problems [7].

This paper describes a clinical protocol for direct extensive low shrinkage composite resin restoration by using an occlusal matrix technique.

\section{CASE REPORT}

Treatment options were presented to patient after initial examination (Figure 1). The patient has no deleterious habits. Initial radiograph demonstrated normality of all structures. Complete-arch impression was made, and a diagnostic cast was fabricated. Desired restoration contours to define shape, form, and occlusal contacts were waxed. Complete-arch impression of the antagonist arch to optimize occlusion was also made.

Acrylic resin was applied over the waxed tooth to copy the anatomic details, and over the adjacent anterior and posterior teeth to allow for exact positioning of the resin during the restoration.

Cavity was prepared by refining the prepared teeth with fine-grit diamond rotary instruments and discs at low speed, without water spray (Figure 2).

Selectively etch enamel with phosphoric acid for 30 seconds was performed and the bonding agent (Silorane Adhesive System/Filtek P90, 3M ESPE) according to the manufacturer's instructions was applied. A thin layer of composite resin (enamel shade A2) was inserted into the matrix with CompoRoller (Kerr). The occlusal matrix was placed intraorally to evaluate the correct position (Figure 3).

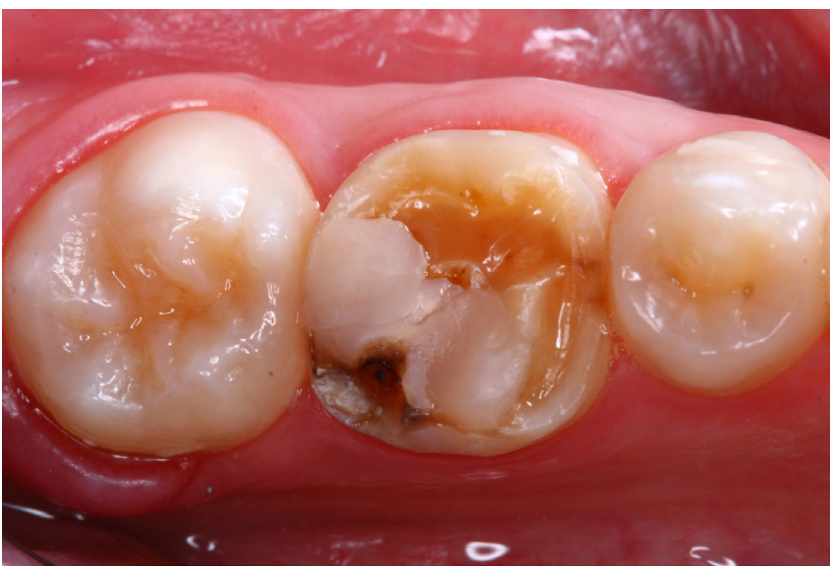

Figure 1. Preoperative view of molar with hypomineralization and compromised aesthetics due to anatomic discrepancies in form, shape, and color.

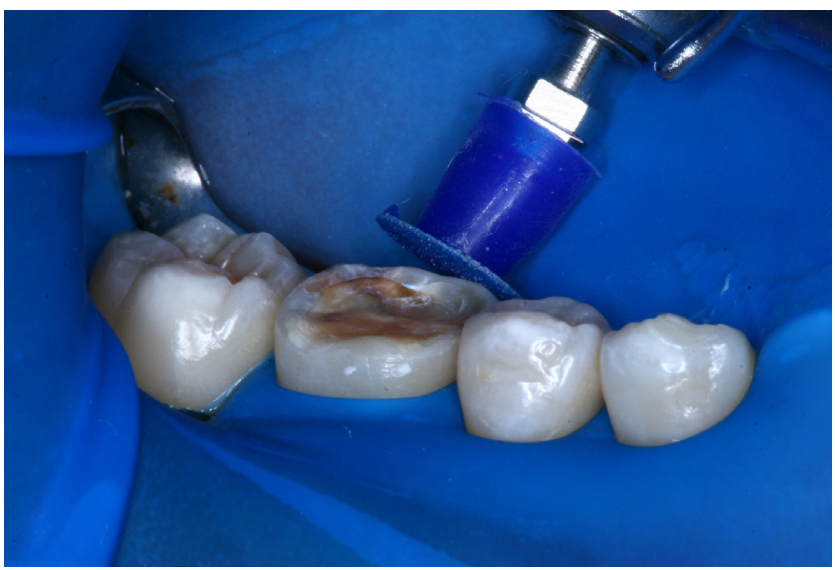

Figure 2. Cavity preparation using minimally invasive technique Composite resin is removed using diamond burs, and cavity preparation is completed using polishing discs.

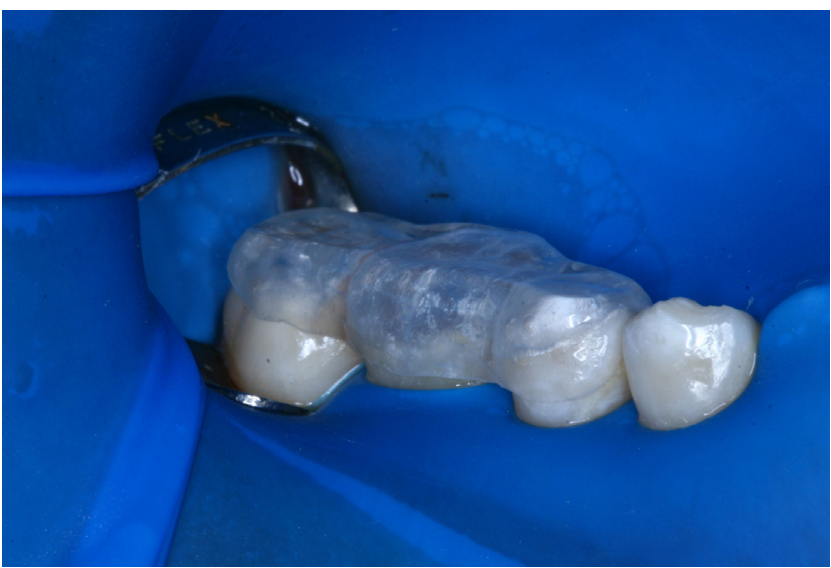

Figure 3. Occlusal matrix in position prior to resin insertion. 
Incremental layering was performed in the deepest portion of the cavity. Definitive layer in the occlusal matrix (Filtek Silorane Restorative System, 3M ESPE) was gently applied (Figure 4).

The matrix was stabilized in the original anatomic position, and pressed down firmly. The last resin increment was polymerized across the occlusal surface by applying light through the matrix while it is being held under pressure to ensure perfect positioning (Figure 5). Light polymerization was performed with an LED device (Radii-cal; SDI) for 120 seconds.

Once curing was complete, occlusal matrix was removed and excess resin using a surgical blade was also removed. Occlusal interferences were evaluated, and necessary adjustments were made (Figures 6 and 7).

Polishing wheels were used to polish the areas (Rotatory Polishing Silicone; Jota Swiss) (Figure 8).

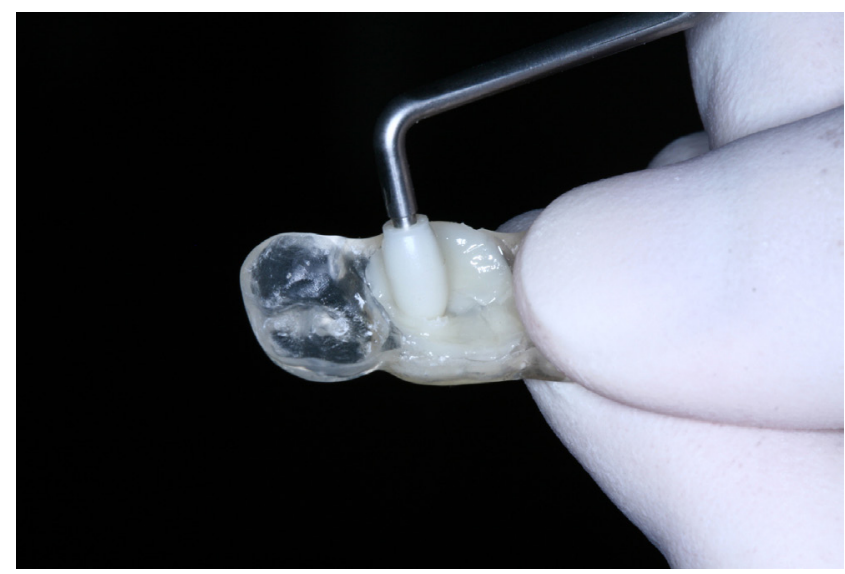

Figure 4. Insertion of resin composite in occlusal matrix.

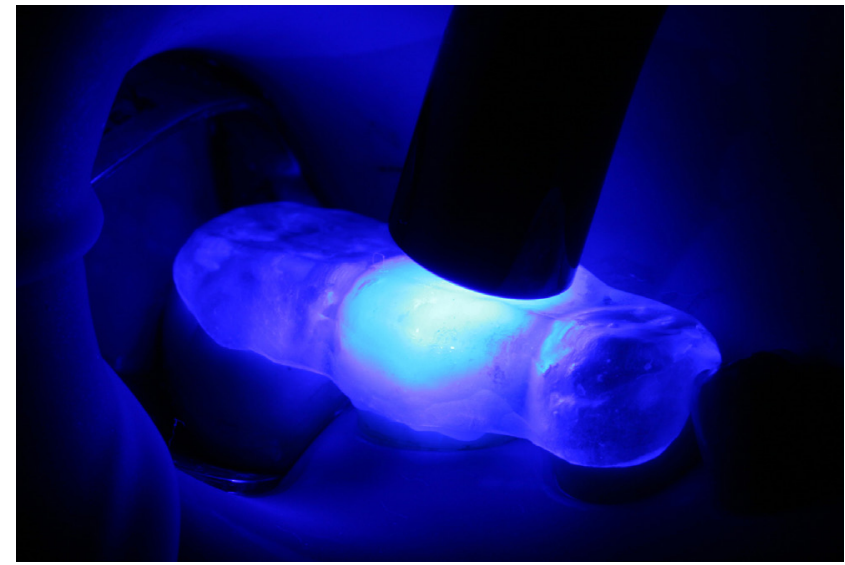

Figure 5. Stabilization of occlusal matrix in position. Resin composite increment is polymerized through matrix.

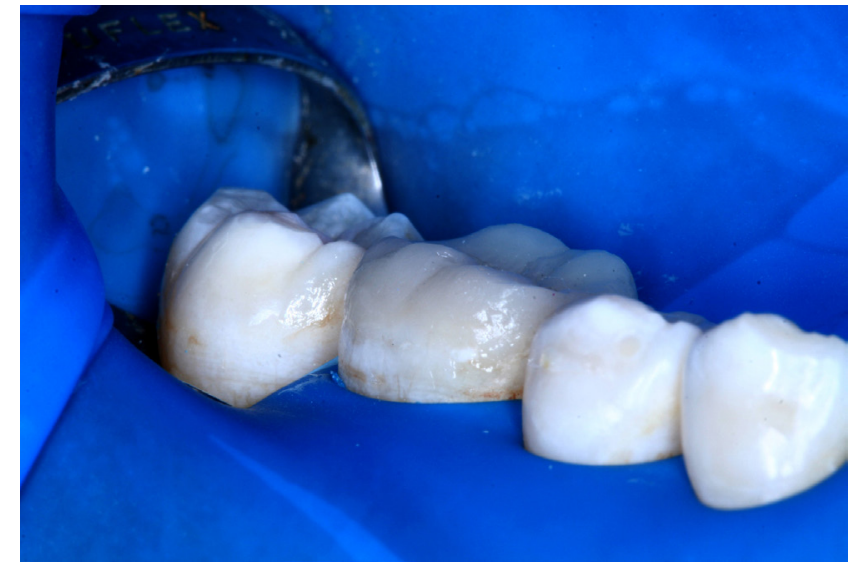

Figure 6. Vestibular view immediately after polymerization of definitive layer of resin composite and removal of occlusal matrix.

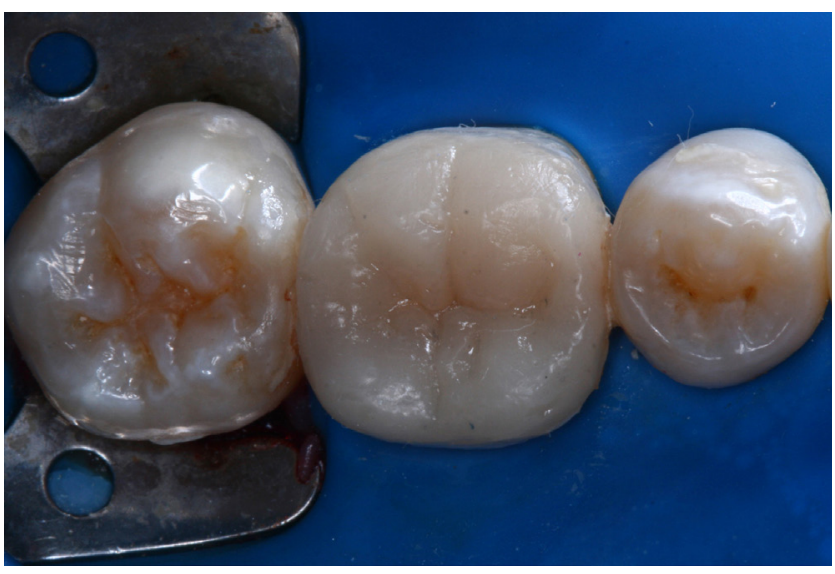

Figure 7. Occlusal view after removal of occlusal matrix.

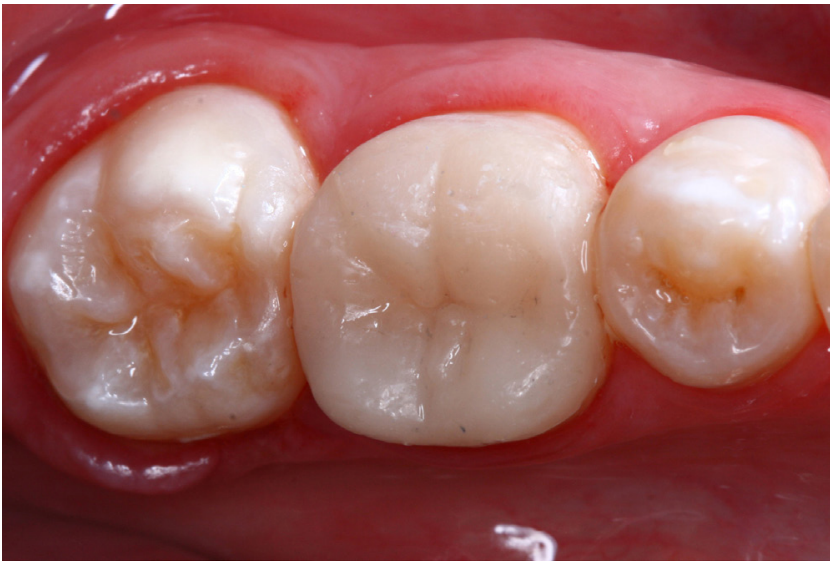

Figure 8. Definitive appearance of restoration, showing anatomic details of the occlusal matrix copied from diagnostic wax cast. 


\section{DISCUSSION}

Regarding the use of occlusal matrixes in the restoration of posterior resin composites, Geddes et al. [4] reported that the technique easily reproduces the original tooth morphology and occlusion. The use of preoperative occlusal matrixes may be recommended as a faster procedure that facilitates the reconstruction of occlusal anatomy, without significantly decreasing the composite microhardness. Also, this technique has the advantage of isolating the resin composite from oxygen, which is beneficial because oxygen hinders polymerization [2].

Silorane-based materials exhibit oxirane rings, which open during the polymerization process, causing expansion, and as a result, produce lower volumetric shrinkage [1]. According to the manufacturer, considering that this polymerization mechanism results in less than $1 \%$ shrinkage, it should reduce the polymerization stress and, consequently, might reduce the incidence of secondary caries, microleakage, postoperative sensitivity, and fractures. Despite the lesser shrinkage, the silorane-based composite resin might increase the stress at the resin-tooth interface because of its structural stiffness and, therefore, might not necessarily reduce the shrinkage stress. Therefore, some authors recommend a layering technique $[3,6]$, similar to the one used in the present case, in which a first bulkier increment was placed, followed by a second and final one using the occlusal matrix, to reduce the possibility of bubble incorporation in the occlusal third. Also, bulk fill composites can be directly positioned, as presented here, without a conventional layering technique due to presence of stress reliever monomers and specific photoinitiators, resulting in less volumetric shrinkage and polymerization stress compared with regular composites [7].

When a tooth is restored with the silorane-based composite, hybridization of the dentin surface is achieved by using a two-step self-etching adhesive system developed exclusively for this purpose. Some studies have shown that self-etching adhesive systems need acid etching when used on enamel, procedure that was performed in the present case. A high degree of conversion and stability of the bond over time can be obtained with a silorane adhesive $[8,9,10,11]$.

In the present case, the diagnostic wax-up was performed because the restoration was relatively large, involving cusp tips and marginal ridges, which are important occlusal contacts in the posterior teeth. If the restoration was performed using a free-hand technique, without the occlusal matrix, it could result in many adjustments and loss of anatomy. In order to obtain the correct anatomical form, without spending significant clinical time during restoration adjustment, the combination between diagnostic wax-up and occlusal matrix technique was chosen, providing predictable and aesthetic results.

\section{CONCLUSION}

The occlusal morphology was accurately reproduced with this technique, which saved time with occlusal adjustment, and achieved esthetically acceptable results. Therefore, this simple technique enabled a conservative functional and aesthetic restoration.

\section{REFERENCES}

1. Schneider LFJ, Cavalcante LM, Silikas N, Watts DC. Degradation resistance of silorane, experimental ormocer and dimethacrylate resin-based dental composites. J Oral Sci 2011;53:413-9. https://doi. org/10.2334/josnusd.53.413

2. Castillo-Oyagüe R, Milward PJ, Martín-Cerrato A, Lynch CD. Effect of preoperative occlusal matrices on the Vickers microhardness of composite disks polymerized with QTH and LED lamps. J Esthet Restor Dent 2015;27:203-12. https://doi.org/10.1111/jerd.12156

3. Ruschel VC, Baratieri LN, Monteiro Júnior S, Andrada MA. Silorane adhesive system: A case report. J Can Dent Assoc 2014;80:e4.

4. Geddes A, Craig J, Chadwick RG. Preoperative occlusal matrix aids the development of occlusal contour of posterior occlusal resin composite restorations: Clinical rationale and technique. Br Dent J 2009;206:315-7. https://doi.org/10.1038/sj.bdj.2009.215

5. Soliman TA, Tubaigy KM, Raffat EM, Al-Agha El. In vitro solubility and wear rates of silorane and dimethacrylate resin based composite restorative materials under different $\mathrm{pH}$ conditions. J Int Oral Health 2015;7:9-13.

6. Van Ende A, De Munck J, Mine A, Lambrechts P, Van Meerbeek B. Does a low-shrinking composite induce less stress at the adhesive interface? Dent Mater 2010;26:215-22. https://doi.org/10.1016/j.dental.2009.10.003

7. Benetti AR, Havndrup-Pedersen C, Honoré D, Pedersen MK, Pallesen U. Bulk-fill resin composites: polymerization contraction, depth of cure, and gap formation. Oper Dent. 2015;40:190-200. https://doi.org/10.2341/ 13-324-L

8. Bastos LA, Sousa AB, Drubi-Filho B, Panzeri Pires-de-Souza F de C Garcia Lda F. Microtensile bond strength of silorane-based composite specific adhesive system using different bonding strategies. Restor Dent Endod 2015;40:23-9. https://doi.org/10.5395/rde.2015.40.1.23

9. Navarra CO, Cadenaro M, Armstrong SR, Jessop J, Antoniolli F, Sergo V et al. Degree of conversion of Filtek Silorane Adhesive System and Clearfil SE Bond within the hybrid and adhesive layer: an in situ Raman analysis. Dent Mater 2009;25:1178-85. https://doi.org/10.1016/j.dental.2009.05.009

10. Kruly PC, Giannini M, Pascotto RC, Tokubo LM, Suga USG, Marques ACR, Terada RSS. Meta-analysis of the clinical behavior of posterior direct resin restorations: Low polymerization shrinkage resin in comparison to methacrylate composite resin. PLoS One. 2018;13:e0191942. https://doi org/10.1371/journal. pone.0191942

11. Mohammadi E, Pishevar L, Mirzakouchaki Boroujeni P. Effect of food simulating liquids on the flexural strength of a methacrylate and siloranebased composite. PLoS One. 2017;12:e0188829. https://doi.org/10.1371/ journal.pone.0188829 